\title{
Driving licences for patients with cardiac pacemakers
}

\author{
Edgar Sowton ${ }^{1}$
}

As the number of patients with implanted cardiac pacemakers increases, the problem of whether such a patient should be allowed to drive a motor vehicle is more frequently raised. In an attempt to obtain information about this problem a postal questionnaire was sent to I30 patients with implanted cardiac pacemakers requesting them to provide anonymously information as to whether they held a current driving licence, were still driving a motor vehicle, or had experienced any accidents since pacemaker implantation. They were also asked how they answered question

* 7 (b) and (f) on Form DLI (revised) 1970 'Application for a licence to drive a motor vehicle' or the equivalent questions on previous forms. Question 7 (b) asked 'Do you suffer from or have you at any time had sudden attacks of disabling giddiness or fainting ?' and 7 (f) asked 'Are you suffering from any other disease or disability likely to cause the driving of a motor vehicle by you to be a source of danger to the public?'.

Postal inquiries were also sent to most of the traffic authorities in the British Isles, to I2 other countries in the world, and information requested from several pacing centres concerning the policy adopted when pacemaker patients attempted to obtain licences. 4

\section{Questionnaire results}

One hundred and seventeen replies were obtained $(90 \%)$ and subsequent percentages are related to $I_{17}$ as 100 per cent unless stated otherwise.

Fifty-six of the patients had held driving - licences $(48 \%)$ and of these, 39 patients admitted to continuing to drive freely (32\% of those replying, or $70 \%$ of those who had held licences at any time). Eight patients had stopped driving before the pacemaker was

\footnotetext{
1 Address: Cardiac Department, Guy's Hospital, London SE1 9RT.
}

implanted because of heart trouble and 3 patients had stopped for other reasons unrelated to heart disease of any sort. Thus, 39 of the $\mathbf{4 5}$ patients holding driving licences at the onset of pacing were still driving $(87 \%$ of the 45 patients).

Of these 39 patients who continued to drive only one reported an accident. This occurred when he skidded on a motor cycle in wet and greasy road conditions and did not involve any other vehicle or pedestrian. The patient was able to remount the motor cycle and continue home. The pacemaker continued to function normally before and after the accident, and it seems extremely unlikely that this was in any way related to pacemaker malfunction.

Question 7, Form DLI (revised) 1970 All patients who hold licences, and many of those who do not, felt able to answer sections (b) and (f) with 'No'. Several patients added comments to qualify their reply. These were all to the effect that the question was being answered accurately and honestly since the pacemaker had completely eliminated dizzy attacks or fainting spells, and that even before pacing the attacks were not 'sudden' or 'disabling'. These views were strongly expressed by several patients including doctors. The overall results indicate that of $5 \mathrm{I}$ patients who did not have driving licences, 9 ( $18 \%$ of the non-drivers, or $8 \%$ of the total who replied) added that they felt able to drive if they wished, or stated that in their opinion other patients with pacemakers should be perfectly safe in driving a car. Overall, of the $117 \mathrm{pa}-$ tients who replied to the questionnaire, 48 $(4 \mathrm{I} \%)$ were either driving or volunteered their view that it would be safe to do so.

Situation in different countries

England and Wales Inquiries were sent 
to the Chief Officers of the Licencing Department of several licencing authorities, including the Greater London Council. Most of these authorities eventually forwarded letters for definitive reply to the Department of the Environment (previously the Ministry of Transport). The Department states the position that medical practitioners who are asked for professional advice on this question would be guided by the content of the report Medical Aspects of Fitness to Drive Motor Vehicles published by the Medical Commission on Accident Prevention. The 1968 edition stated (pp. 15-16) that patients with cardiac pacemakers should be advised not to drive. Under the heading 'Suggestions for Advice to $\mathrm{Pa}$ tients', it is stated that patients with this condition should not be allowed to drive particularly if a pacemaker has been inserted. The authors also comment that more reliable pacemaking systems will probably emerge so that the 1968 recommendation might be reversed. In the most recent edition (1971) the recommendation is in fact changed, and it is recommended that certain pacemaker patients can be allowed driving licences provided supporting evidence from a physician is available.

This view is not compatible with a directive issued to County Medical Officers by the Central Licensing Authority in Swansea dated July 1971. This states that patients with cardiac pacemakers cannot hold driving licences. As a result of this directive many patients have had their licences revoked.

The situation is further complicated by the fact that several patients in this series had approached the Department of the Environment and requested guidance on this point. All were told that a pacemaker was no bar to obtaining a driving licence provided the circumstances were declared in the application. Several patients had also approached the Legal Advices Service of the Automobile Association and were all advised that an implanted cardiac pacemaker would not be a bar for an individual to obtain a driving licence provided he was otherwise entitled. These patients were told that they could be considered as having 'controlled medical circumstances' in the same way as a controlled diabetic.

The present situation in England and Wales can therefore only be described as confused with different Licencing Authorities adopting different views, some patients having their licence revoked, and others being allowed driving licences after medical examinations.

Scotland Clinical practice varies over the country, and in Edinburgh patients are specifically told not to drive public service vehicles. The Scottish Home and Health Department have been unable to find any reports of road accidents involving pacemaker patients.

United States The situation differs in detail from State to State but in general there is no objection to an individual having a licence to drive an automobile as long as he would otherwise qualify and can provide a physician's certificate that the pacemaker is functioning normally and the patient continues under medical supervision. The Department of Motor Vehicles in California requires supporting letters from the physician at the end of each 6-month period.

Other countries In all cases where information is available pacemaker patients were allowed driving licences for private vehicles (but not for heavy duty or public service vehicles) provided support was available from the cardiologist or physician. In Australia individual decisions are made by the Police Surgeon of the State and a similar policy is adopted in Hungary, Iceland, Japan, West Germany, and East Germany. In Poland physical examination at the Health Service Centre is usually required in addition to medical reports, but patients are not denied a licence solely because of a cardiac pacemaker. In Belgium the decision to recommend issue of a driving licence is based largely upon the advice of the patient's private physician, and the Belgian Cardiac Society has issued general guidelines. These state that licences should be granted to certain pacemaker patients and though this advice has no legal standing the guidelines are followed in practice.

Pacemaker patients must surrender their driving licences in Holland until a panel of medical specialists has given approval for it to be renewed; new applicants are considered in the same way, and in both situations the medical details are reviewed by cardiologists who are not concerned in the direct treatment of the patient. In France the licencing regulations are complex, with seven categories, in which medical examination is required for large vehicles, those carrying fare-paying passengers, or for invalid carriages. Pacemaker patients in good health are allowed licences for private cars only.

\section{Literature review}

A report by Edhag who interviewed I 39 patients undergoing long-term pacing in Sweden reported that more than one-third were in possession of a driving licence and one-half of these actually drove a car (Edhag, 1969). 
- Edhag notes that the Swedish National Board of Health supported the application for driving licences, with the proviso that the patient should be under continuous medical treatment and should present a health certificate every year. He was unable to find any evidence of an accident related to pacemaker malfunc- tion, and A. Holmquist (I97I, personal communication) reports that investigations carried out by the Ministry of Communications in Sweden also failed to obtain any details of accidents caused by pacemaker patients. It is of interest to note that very few of the licencing authorities in Britain who were approached for this investigation had any knowledge of pacemaker patients holding licences in their area. During this inquiry no evidence emerged of accidents related to pacemaker patients in any country. Crancer and O'Neall (1970) carried out an extensive analysis of drivers in Washington in relation to licence restrictions because of heart disease. The driving records of

" 44 pacemaker users were compared with comparable samples of drivers with heart disease and with non-restricted drivers selected to match the pacemaker patients in terms of age, sex, and city of residence. There were no significant differences between the 3 groups in terms of accidents or traffic violations and

- the authors conclude that the users of pacemakers do not present a particular problem. Heinz, Scheppokat, and Kalmar (1970) have considered the position in West Germany and conclude that patients with properly functioning pacemakers who are under continuing outpatient supervision should be allowed licences to drive private cars but not to act as professional drivers; the concensus of an

- opinion poll carried out mainly in the United States by P. M. Yurchak (1970, personal communication) was very similar. P. Davidson and L. Abrams (I97I, personal communication) are of the opinion that selected patients with induction pacemakers should be allowed driving licences, but Whitaker feels that all mpacemaker patients should be advised against driving (1970), and Oberwittler (1967) describes a single case with ectopic beats following pacemaker implantation and expresses the view that this patient should not be allowed to drive. The view expressed in the 1971 edition of Medical Aspects of Fitness to - Drive Vehicles, that selected pacemaker patients should be allowed driving licences, is supported by the Chief Medical Officer to London Transport (Raffle, 197I).

It is relevant to note that conditions such as paroxysmal tachycardia, aortic stenosis, or incompetence, even when complicated by syncope and anginal pain have not been con- sidered absolute contraindications to the issue of a driving licence, though driving is certainly discouraged (Medical Aspects of Fitness to Drive Vehicles). In relation to epilepsy licences may be issued when the patient has been free from all attacks for at least three years with or without treatment, and patients with treated hypertension are also allowed to drive providing they have not experienced vertigo, transient faintness, loss of consciousness, or postural hypotension.

In an investigation carried out in the Southampton area Grattan and Jeffcoate (1968) investigated 9390 drivers and found no evidence that cardiac pacemakers were a cause of accidents in that series. E. Gratton (1970, personal communication) has been able to check the Road Research Laboratory details of roro drivers and riders of motor cycles or scooters who were involved in serious injury in road accidents investigated between 1965 and 1969. No pacemakers were in use among these riders or drivers, and there were only very few cases in which sudden illness was thought to have been the cause of an accident. Herner, Smedby, and Ysander (1966) concluded that deaths at the wheel from any cause were not associated with a high incidence of serious injury to other road users.

It is now very rare for pacemakers to fail suddenly and the usual mode is a change in rate resulting from battery exhaustion; when this occurs prematurely (i.e. within the first 18 months) it may be secondary to some other component failure but even under these circumstances it is rare for pacemakers to alter their performance dramatically. Even if a pacemaker ceases to function it is by no means certain that the patient will have an AdamsStokes attack at that moment-or at all-so that the overall likelihood of Adams-Stokes attacks occurring during driving because of sudden pacemaker failure must be extremely low. There are, however, certain groups of patients in whom a higher risk can be identified. These include patients who are known to have no idioventricular rhythm (or an extremely slow rate), patients with previous pacing failure due to exit block (high threshold) in whom pacing has been re-established with drugs, those with new and relatively untried equipment, those in whom the physician has reason to doubt the integrity or stability of the electrode, and those whose pacemaker batteries may run down unexpectedly because they are not under continual outpatient supervision. It is suggested that in such cases an application for a driving licence should not be supported.

In all the countries sampled, with the excep- 
tion of Britain, it is possible for selected pacemaker patients to obtain driving licences for private cars. In Britain it is possible for patients to obtain licences in some areas only despite the directive 897 I from the Centralised Licencing Authority (July 30, 1971) informing licencing authorities that pacemaker patients cannot hold a licence. Such evidence as is available suggests that many pacemaker patients do in fact drive vehicles and that they do not represent a significantly increased hazard. There seems little reason why the system of issuing licences which is recommended in the 1971 edition of Medical Aspects of Fitness to Drive Motor Vehicles and which has been successfully adopted by many other countries should not become common policy throughout Britain.

\section{References}

Centralised Licencing Authority, Swansea (197I). Directive 897I, 30 July 197 I.

Crancer, A., and O'Neall, P. (I970). A record analysis of Washington drivers with licence restrictions for heart disease. Northwest Medicine, 69, 409.

Edhag, O. (1969). Long term cardiac pacing. Experience of fixed pacing with an endocardial electrode in 260 patients. Acta Medica Scandinavica, Suppl., 502.

Grattan, E., and Jeffcoate, G. O. (1968). Medical factors and road accidents. British Medical fournal, I, 75.

Heinz, N., Scheppokat, K. D., and Kalmar, P. (1970). Schrittmacherpatienten im Strabenverkehr Sonderabdruck aus 'Hefte zur Unfallheilkunde', Heft 102: Verhandlungen der Deutschen Gesellschaft für Unfallheilkunde Versicherungs, Versorgungs und Verkehrsmedizin e.V. 33. Tagung vom 19 bis 21 Mai 1969 in Nurnberg.

Herner, B., Smedby, B., and Ysander, L. (1966). Sudden illness as a cause of motor vehicle accidents. British fournal of Industrial Medicine, 23, 37.

Medical Aspects of Fitness to Drive Motor Vehicles (1968 and 1971). The Medical Commission on Accident Prevention, London.

Oberwittler, W. (1967). Die Beurteilang der Kraftfahrtauglichkeit bei Trägern eines künstlichen Herzschrittmachers. Monatsschrift für Unfallheilkunde, Versicherungs- Versorgungs- und Verkehrsmedizin, 70, 130.

Raffle, P. A. B. (1971). Fit to drive ? Health Trends, 3, 22.

Whitaker, W. (1970). Cardiology. World Medicine, 5 (February: Review of the Year), 51.

Requests for reprints to Dr. Edgar Sowton, Cardiac Department, Guy's Hospital, London SEI 9RT. 